\title{
Implementation Influence of ISO9000 on Organization's Performance
}

\author{
Amal AL Othman ${ }^{1} \&$ Said Taan EL Hajjar ${ }^{2}$ \\ ${ }^{1}$ Council of Representatives, Manama, Kingdom of Bahrain \\ ${ }^{2}$ College of Business, Ahlia University, Kingdom of Bahrain \\ Correspondence: Said Taan EL Hajjar, College of Business, Ahlia University, Kingdom of Bahrain. E-mail: \\ salhajjar@ahlia.edu.bh
}

Received: January 27, 2017

Accepted: May 23, 2017

Online Published: June 7, 2017

doi:10.5539/ijbm.v12n7p100

URL: https://doi.org/10.5539/ijbm.v12n7p100

\begin{abstract}
Implementing the International Organization for Standardization (ISO9000) in Bahrain Council of Representatives offers many prospects to diversify Bahrain's Parliament and raise management development and duties. This paper entirely explores the potential items of customer focus, leadership, people's involvement, and continual improvement, which will be used as a scale to measure the impact of ISO 9000 on Bahrain Council of Representatives performance and other private sector organizations to recognize that potential. This research work is mainly designed based on one of quantitative approaches, which is the survey questionnaire. Data was collected from Council of Representative's Staff in the Kingdom of Bahrain by distributing the questionnaire randomly to Council of Representative's employees and consequently analyzed through quantitative analysis methods. Overall findings show that all items appear to be useful and contribute to the overall reliability of their corresponding construct. This research work will help define best items and constructs for stakeholders' who are interested in applying ISO9000 standards in the organizations, prioritize improvement of employees and enhance performance relative to shareholders' expectations and liable organization development. This paper fills a prevailing gap by providing a distinctive reliable assessment scale of such effectiveness and comprehensive assessment measure through an organized analysis of pertinent arcade data in the kingdom of Bahrain.
\end{abstract}

Keywords: customer focus, leadership, people's involvement, continual improvement, organization's performance

\section{Introduction}

Nowadays, the institutions are searching for improving their existing products and services to compete with others that can progressively push the organization position to better level and gain more benefits and profits. One way of improvement is implementing the quality system that can develop the institution operations and processes, help institution to produce by high quality and low cost, reduce mistakes, errors and reworks, change and improve the productivity methods and add more value to all organization output. Another way is self-confidence and apparent success of leadership studies in general and transformational leadership in particular (Alvesson \& Kärreman, 2016). They suggested that the ideological character of these approaches lead for their success. Houdek (2016) clarified that the worth of the perception of local thinking in clearing up decisions taken by managers is proven by a tiny theoretical review of numerous empirical studies on local economic, workers' compensations, and gender equality. This study targets to examine the influence of implementing ISO 9000 on private sector performance. The case study will be from Council of Representatives in the Kingdom of Bahrain. The author will measure the influence of customer focus, leadership, people's involvement, and continual improvement, which are main four principles of ISO 9000, on overall performance.

\subsection{A Glance at ISO 9000}

ISO includes quality standards and measures to take them into account through producing products or delivering services to achieve consumer demands at the end. Also, it develops the organization infrastructure and environment to become clear and safe. There are multiple methods to develop and organize the services quality. Today, ISO 9000 is one of the most competitive edges over their competitors. The ISO 9000 contains ISO's best known standards and it covers the aspects of quality management. Guidance and tools are provided to the organizations for making it sure that their services or products are meeting the requirements of consumers, and quality is constantly improved. The standards can be implemented on different kind of organizations, whatever 
its size or product, or in any activity sector. ISO9000 is so far the most commonly used certification by the organizations. It was introduced to meet users' needs and requirements, as well as it improves the operational performance.

The International Organization for Standardization (ISO) issued the ISO 9000 sets of standards in 1987. The sets of standards is to "provide guidance and tools for organizations that want to ensure that their products and services consistently meet customer's needs, and that quality is consistently improved" (ISO, 2014). These standards have been issued to guide organizations to implement quality management systems (ISO, 2005). Within this set of standards, the ISO 9000 family includes four different groups:

ISO 9001:2008 (ISO, 2008) sets out the quality management system requirements where an organization can explain its capability to deliver products and services that satisfy customer and regulatory requirements.

ISO 9000:2005 (ISO, 2005) describes basic quality management system and explains the vocabulary used. It aims to create basic understanding ISO standards. Moreover, it inserts eight principles of quality management and the process method for continual improvement (ISO, 2005; ISO, 2009b).

ISO 9004:2009 (ISO, 2009a) gives guidelines of quality management system by effective and efficiency way. It aims at enhancing organizations for managing long-term success. It is recommended for organizations that are willing to provide the benefits gained from ISO 9001 and to systematically and continually improve the organization's overall performance.

ISO 19011:2011 (ISO, 2011) provides guidelines for internal and external auditing of quality management system. It includes information on the audit programs, how to reach an internal or external audit, and auditor efficiency.

\subsection{Principles of ISO 9000}

ISO 9000 standards are based on eight principles. These principles are used as a scope to improve performance (ISO, 2012).

- Customer focus: "Organizations depend on their customers and therefore should understand current and future customer needs and meet their requirements and strive to exceed customer expectations."

- Leadership: "Leaders establish the purpose and direction of the organization. They should create and maintain the internal environment in which people become involved in achieving the organization's objectives."

- People" Improvement: "People at all levels are the core of an organization and their full involvement enables their abilities to be used for the organization's benefit."

- Process approach: "Desired result is achieved more efficiently when activities and related resources are managed as a process."

- System approach to management: "Identifying, understanding and managing interrelated processes as a system contributes to the organization's effectiveness and efficiency in achieving its objectives."

- Continual improvement: "Continual improvement of the organization's performance should be a constant objective of the organization."

- Factual approach to decision making: "Effective decisions are based on the analysis of data and information."

- Mutually beneficial supplier relationships: "organization and its suppliers are interdependent and a mutually beneficial relationship helps the ability of both to create value."

\subsection{A Glance at Bahrain Council of Representatives}

Parliament or the council of Representatives is the legislative body representing the legislative authority at Kingdom of Bahrain. It consists of a group of 40 individuals called representatives. they are chosen by the citizens of the people registered on the electoral lists in the election or ballot in secret, direct and have the full authority of the Parliament regarding the issuance of legislations and laws, or canceled and the ratification of international and external agreements concluded by the representatives of the executive power. The General Secretariat is technical and administrative staff aide to council members for the performance of parliamentary duties, and legislation, political, financial, or related to his activity in the Parliamentary Group, connected device information and technical parliamentary deputies. General Secretariat administrative institution is seeking to recruit expertise, researchers and staff who are able to perform their technical and administrative efficiency. This recruitment aims to assist member on the performance of parliamentary duties, and to remove obstacles and difficulties hinder them from performing parliamentary duties, and assist them in the performance of these tasks. 


\subsection{Organizational Problem in Bahraini Institutions}

Today, the organizations in the Kingdom of Bahrain are becoming more aware and interested in quality because the non- certificated organizations are facing a high decline in their productivity or reputability. The different types of organizations need to implement some kind of quality system to develop the performance and moving toward satisfying the consumers. The most famous approach used in this field is ISO9000. In the recent years, ISO9000 certification is considered as a competitive advantage. Competition among the organizations in Bahrain is increasing daily. This research will investigate to what extent the ISO9000 implementation impacts the organization performance and to measure the most quality factors that influence the organization's performance.

ISO9000 is the world's speedy growing quality system. Its main target is to build trust between the end user of the product and service of the organization. The main gap in the current study lies in the insufficient researches that have examined the relationship between ISO 9000 and organization's performance, especially in Bahraini organizations.

\subsection{Rational of the Study}

Many institutions invest their efforts to delivering products and services with high level of quality. They try to develop systematic procedures to raising the financial and non-financial benefits by applying the standards of ISO 9000 (Piskar, 2007). The study of Piskar (2007) investigated the impact of ISO 9000 on customer satisfaction through 212 certified companies. The research findings in Slovenian firms emphasize the ISO 9000 quality standard's impact on better satisfying customers' requirements, but not the direct influence on business success.

The firms are looking for the ways to expand and improve their business. (Mangula, 2013) researched for the effect of ISO 9001 certification on manufacturing industries performance in Tanzania. The author collected 40 selected respondents using sample random approach. The findings in this paper reveal that the quality of products as well its quantity (volume) has been improved and the production costs have been reduced. Also, the customers will be satisfied and become loyal.

The study by (Cagnazzoet al, 2010) showed the positively effects of ISO 9000 on the business performances. The effects on the performance were internal and external to the firm. The external effects were divided by impact on: a) international commerce, b) suppliers, c) customers, d) shareholders and, e) market. The internal effects were divided by impact on: a) quality system, b) product/service, c) competitiveness, and) financial performance, e) human resource and f) environment (Ollila, 2012).

In this study, the author was researched for the various methods in which a firm can use the ISO 9001 characteristics to improve its operations. The constructs and items were adopted after analyzing different research articles' results, which showed that ISO 9001 had good features in improving the organization's performance, such as internal, external audits and the control of production.

So many local and international organizations are seeking for implementing ISO9000 standards because of its positive effect on improving productivity, decreasing mistakes and reworks, and reducing cost as stated by the researchers and experts. The study will be useful for organizations that are looking for implementing quality system standards and the impact of those standards on the organization's performance. The finding of this study will be expected to provide a clear picture about the effectiveness of the ISO 9000 on different organizational performance. Moreover, it will highlight the advantages of the ISO 9000 and provide evidence and assurance to any organization that thinks about being certified. This study will measure the impact of implementing ISO 9000 on the organization's performance, especially on one of most important organization in the kingdom of Bahrain. There are limited researches on this field in kingdom of Bahrain. Also, the research will measure the relationship between customer focus, leadership, involvement of people from one side with continual improvement on another side. In addition, the research will investigate for the most influencing principles on performance.

\subsubsection{Bahrain Principles of ISO 9000}

Based on the purpose of this research, particular constructs influencing the private sector organizations identified from the associated literature. Four of them were initiated to be related to the private organizations in Bahrain. For the purpose of this research, all constructs are referred to as Bahrain Principles of ISO (BPISO) verified in Table 1. These principles are used as a scope to improve performance (ISO, 2012). 
Table 1 . Four quality management principles identified by researchers

\begin{tabular}{ll}
\hline Principle & Bahrain Principle ISO (BPISO \\
\hline Customer focus & "Organizations depend on their customers and therefore should understand current \\
& and future customer needs and meet their \\
& requirements and strive to exceed customer expectations." (ISO, 2012a). \\
& "Leaders establish the purpose and direction of the organization. They should \\
Leadership & create and maintain the internal environment in which people become involved in \\
& achieving the organization's objectives." (ISO, 2012a). \\
"People at all levels are the core of an organization and their full & involvement enables their abilities to be used for the organization's \\
& benefit." (ISO, 2012a). \\
"Continual improvement of the organization's performance should be a constant & \\
Continual improvement & objective of the organization." (ISO, 2012a). \\
\hline
\end{tabular}

\section{Method}

The methodology used in this research aims at providing the method used to collect data based on the research conceptual model along with the hypotheses. It describes the primary data approach that has been used in this research, and defines the size of the population and sample. In addition, the researcher will analyze the data collected through the survey.

\subsection{Research Design}

The study is based on a quantitative analysis of primary data in lieu of staff perspectives employed at Council Representatives in the Kingdom of Bahrain. The method used in this research primarily follows a quantitative design which is aimed at forming an efficient structure and organized analysis, after checking for the strength of the conceptual model. Descriptive analysis is employed to an objective dataset obtained by surveying employees at the Council Representatives of Bahrain.

\subsection{Data Collection and Sampling Techniques}

Primary data was the common research methods. Primary Data was collected via drop-off paper questionnaires aimed at reducing the possibility of sample bias that might result from following online surveys. This approach was functioned only to those who were employed at the Council Representatives of Bahrain.

Stratified random sampling is functioned in the research. Precisely, the technique of uneven stratified random sampling was implemented as it is more promising to guarantee presence of diverse physiognomies of the population, tolerable contribution of small size strata, and to estimate proportional statistics between strata (Blac, 2012; Zikmund, 2011). Table 2 reveals the sampling design carried out in this research.

Table 2. Four quality management principles identified by researchers

\begin{tabular}{llllll}
\hline Council Representatives & \multicolumn{5}{c}{ Staff } \\
\hline Position & Employee & Supervisor & Head of Department & Director & Total \\
Population Size & 155 & 52 & 30 & 13 & 250 \\
Percentage of Population & $62 \%$ & $20.8 \%$ & $12 \%$ & $5.2 \%$ & $100 \%$ \\
Recommended Sample Size* & 132 & & & & \\
Distributed Questionnaires & & & & 8 & 200 \\
Paper Survey & 129 & 41 & 22 & 0 & 0 \\
E-Survey & 0 & 0 & 0 & &
\end{tabular}

* Statistical parameters for sample size calculation were fixed as follows: 95\% level of confidence and 5\% margin of error.

\subsection{Research Hypotheses}

Based on the sampling technique implemented in this research, the researcher develops the proposed hypotheses as shown below.

H1: Customer focus has influence on the performance of organization. 
$\mathrm{H} 2$ : Leadership has influence on the performance of organization.

H3: Involvement of people has influence on the performance of organization.

H4: Continual improvement has influence on the performance of organization.

\subsection{Data Analysis Methods}

The researcher has assumed the organization performance (OP) as the dependent variable, and it was influenced by applying BPISO, some of ISO9000 principle variables, which were customer focus (CF), leadership (LE), involvement of people (IP), and continual improvement (CI). Descriptive statistical analyses were applied using SPSS Version 18. Pearson correlation was used to test the relationship between each of the independent variables from one side and the dependent variable on another side (Schumacker, 2015). Regression analysis was used to test the satisfaction of the hypotheses (Lee et al., 2013).

\subsection{Reliability and Validity}

In order to identify validity and reliability of the proposed scale, the research conducts pilot study by analyzing 120 responses which are selected randomly from the 200 respondents. The researcher measures the internal consistency which is a useful method for testing reliability and construct validity. To be sure that the scale is valid and reliable, Cronbach's alpha and internal consistency tests among items and constructs were employed. It had been required to calculate overall Cronbach's alpha to know the extent of construct reliability which was compared with the cutoff value of 0.6 , and examine the internal consistency among the items and constructs by calculating item to item correlation (acceptable value $>3$ ), item to total correlation (acceptable value $>0.5$ ), and Cronbach's alpha if item deleted (acceptable value < Overall Cronbach's alpha) (EL Hajjar, 2016). By using SPSS version 18, the comparison was clear and accurate.

\subsubsection{Customer Focus Construct Output}

Four items explain this construct.

- Identifying the customer needs and their expectations. (CF1)

- Checking organization goals are related to customer needs and their expectations. (CF2)

- Examining the satisfaction of customers and taking actions depend on the findings. (CF3)

- Changing customer needs into requirements of ISO. (CF4)

As shown in Table 3, Overall alpha is 0.938 , which indicates satisfied internal consistency among the four levels of customer focus item. Moreover, it indicates that each item is correlated well with each of the other items $(0.821>0.3,0.811>0.3$, and $0.711>0.3,0.889>0.3,0.756>0.3,0.746>0.3)$. In addition, Table 3 indicates that each item correlates well with overall total correlation of the other items $(0.842>0.5,0.900>0.5,0.890>$ 0.5 , and $0.780>0.5$ ). Although Cronbach's Alpha would increase from 0.938 to 0.941 if CF4 item was deleted, there is a statistical reason not to drop it as it correlates well with each of the other items and it correlates well with overall total correlation of the other items. Thus, all items appear to be useful and contribute to the overall reliability of customer focus construct.

Table 3. Reliability statistics of customer focus construct

\begin{tabular}{lll}
\hline Cronbach's Alpha & & .938 \\
\hline Item-Item Correlation & CF1<--> CF2 & .821 \\
& CF1<--> CF3 & .811 \\
& CF1<--> CF4 & .711 \\
& CF2<--> CF3 & .889 \\
& CF2<-- CF4 & .756 \\
Corrected Item-Total Correlation & CF3<-- CF4 & .842 \\
& CF1 & .900 \\
Cronbach's Alpha if Item Deleted & CF2 & .890 \\
& CF3 & .780 \\
\end{tabular}




\subsubsection{Leadership Construct}

Four items explain this construct.

- Taking into account the desires of all concerned parties including customers, owners, workers, providers, financiers, domestic communities and society as a whole. (LE1)

- Explaining the vision. (LE2)

- Making shared values, justice, and moral role at all parties of the organization. (LE3)

- Providing the required resources, training and freedom to act with responsibility for all staff. (LE4)

As shown in Table 4, overall alpha is 0.912 , which indicates significant internal consistency among the four levels of leadership construct. Moreover, it indicates that each item is correlated well with each of the other items $(0.768>0.3,0.698>0.3$, and $0.693>0.3,0.722>0.3,0.690>0.3,0.810>0.3)$. In addition, Table 4 indicates that each item correlates well with overall total correlation of the other items $(0.790>0.5,0.804>0.5,0.823>$ 0.5 , and $0.804>0.5$ ). Cronbach's Alpha would decrease from 0.912 to $0.894,0.885,0.880$ or 0.884 if either of LE1, LE2, LE3, or LE4 item was deleted, then there is a statistical reason not to drop any of these items. Thus, all items appear to be useful and contribute to the overall reliability of leadership construct.

Table 4. Reliability statistics of leadership construct

\begin{tabular}{lll}
\hline Cronbach's Alpha & & .912 \\
\hline Item-Item Correlation & LE1<--> LE2 & .768 \\
& LE1<--> LE3 & .698 \\
& LE1<--> LE4 & .693 \\
LE2<--> LE3 & .722 \\
& LE2<--> LE4 & .690 \\
Corrected Item-Total Correlation & LE3<--> LE4 & .810 \\
& LE1 & .790 \\
& LE2 & .804 \\
& LE3 & .823 \\
Cronbach's Alpha if Item Deleted & LE4 & .804 \\
& LE1 & .894 \\
& LE2 & .885 \\
& LE3 & .880 \\
\hline
\end{tabular}

\subsubsection{Involvement of People Construct}

Three items explain this construct.

- Getting staff understanding the significant of their assistance and their role in the organization. (IP1)

- Getting staff freely participating knowledge and experiment. (IP2)

- Getting staff widely discussing problems and cases. (IP3)

As shown in Table 5, overall alpha is 0.873 , which indicates satisfied internal consistency among the three levels of involvement of people construct. Moreover, it indicates that each item is correlated well with each of the other items $(0.656>0.3,0.601>0.3$, and $0.831>0.3)$. In addition, Table 5 indicates that each item correlates well with overall total correlation of the other items $(0.656>0.5,0.833>0.5,0.786>0.5)$. Although Cronbach's Alpha would increase from 0.873 to 0.907 if IP1 item was deleted, there is a statistical reason not to drop it as it correlates well with each of the other items and it correlates well with overall total correlation of the other items. Thus all items appear to be useful and contribute to the overall reliability of Improvement of people construct. 
Table 5. Reliability statistics of involvement of people construct

\begin{tabular}{lll}
\hline Cronbach's Alpha & & .873 \\
\hline Item-Item Correlation & IP1<--> IP2 & .656 \\
& IP1<--> IP3 & .601 \\
& IP2<--> IP3 & .831 \\
Corrected Item-Total Correlation & IP1 & .656 \\
& IP2 & .833 \\
Cronbach's Alpha if Item Deleted & IP3 & .786 \\
& IP1 & .907 \\
& IP2 & .750 \\
& IP3 & .792 \\
\hline
\end{tabular}

\subsubsection{Continual Improvement Construct}

Three items explain this construct.

- Using an appropriate organization-wide method to continual improvement of the performance. (CI1)

- Deciding that the continual improvement of operations and systems is a goal for each employee. (CI2)

- Founding objectives to guide, and measures to path continual improvement. (CI3)

As illustrated in Table 6, overall alpha is 0.914 , which indicates significant internal consistency among the three levels of continual improvement construct. Moreover, it indicates that each item is correlated well with each of the other items $(0.751>0.3,0.768>0.3$, and $0.823>0.3)$. Table 6 indicates that each item correlates well with overall total correlation of the other items $(0.796>0.5,0.838>0.5,0.852>0.5)$. Cronbach's Alpha would decrease from 0.914 to $0.903,0.885,0.866$ or 0.855 if either of CI1, CI2, or CI3 items was deleted, and then there is a statistical reason not to drop any of these items. Thus, all items appear to be useful and contribute to the overall reliability of continual improvement construct.

Table 6. Reliability statistics of continual improvement construct

\begin{tabular}{lll}
\hline Cronbach's Alpha & & .914 \\
\hline Item-Item Correlation & $\mathrm{CI} 1<-->\mathrm{CI} 2$ & .751 \\
& $\mathrm{CI} 1<-->\mathrm{CI} 3$ & .768 \\
& $\mathrm{CI} 2<-->\mathrm{CI} 3$ & .823 \\
Corrected Item-Total Correlation & $\mathrm{CI} 1$ & .796 \\
& $\mathrm{CI} 2$ & .838 \\
& $\mathrm{CI} 3$ & .852 \\
Cronbach's Alpha if Item Deleted & $\mathrm{CI} 1$ & .903 \\
& $\mathrm{CI} 2$ & .866 \\
& $\mathrm{CI} 3$ & .855 \\
\hline
\end{tabular}

\subsubsection{Organization Performance Construct}

Four items explain this construct.

- In General, The organization performance will be improved after applying ISO 9000. (OP1)

- ISO 9000 will provide high level of control on workflows. (OP2)

- ISO 9000 will provide an accurate work logs and decrease re-work times. (OP3)

- Applying ISO 9000 will enhance the organization to measure the performance. (OP4)

As shown in Table7, overall alpha is 0.949 , which indicates significant internal consistency among the four levels of organization performance construct. Moreover, it indicates that each item is correlated well with each of the other items $(0.812>0.3,0.774>0.3$, and $0.831>0.3,0.864>0.3,0.878>0.3,0.788>0.3)$. In addition, Table 7 indicates that each item correlates well with overall total correlation of the other items $(0.852>0.5,0.915>$ 
$0.5,0.855>0.5$, and $0.889>0.5$ ). Cronbach's Alpha would decrease from 0.949 to $0.941,0.922,0.940$ or 0.930 if either of OP1, OP2, OP3, or OP4 items were deleted, and then there is a statistical reason not to drop any of these items.

Table 7. Reliability Statistics of Organization Performance Construct

\begin{tabular}{lll}
\hline Cronbach's Alpha & & .949 \\
\hline Item-Item Correlation & OP1<--> OP2 & .812 \\
& OP1<--> OP3 & .774 \\
& OP1<--> OP4 & .831 \\
& OP2<--> OP3 & .864 \\
& OP2<--> OP4 & .878 \\
& OP3<--> OP4 & .788 \\
Corrected Item-Total Correlation & OP1 & .852 \\
& OP2 & .915 \\
& OP3 & .855 \\
& OP4 & .889 \\
Cronbach's Alpha if Item Deleted & OP1 & .941 \\
& OP2 & .922 \\
& OP3 & .940 \\
& OP4 & .930 \\
\hline
\end{tabular}

Thus, all items appear to be useful and contribute to the overall reliability of leadership construct. Thus, the scale is highly reliable and acceptable, and the construct validity is satisfied.

\section{Descriptive Analysis}

The descriptive statistics showed the data gathered from participates as a numbers for each items in the questionnaire.

\subsection{The Frequencies of Demographic Information}

The first part of questionnaire is Demographic information which gathered the personal data of participates. By using SPSS, the researcher analyzed the data to present the frequencies of gender, Age, Work experience, Qualifications, and job position. A total of responses were 200, which answer the research questionnaire to measure the extent of influence of implementing ISO 9000 on organization performance. Table 8 gives the number of valid responses.

Table 8. Responses Statistics

\begin{tabular}{ccccccc}
\hline & & Gender & Age & Work Experience & Qualification & Position \\
\hline \multirow{2}{*}{ N } & Valid & 200 & 200 & 200 & 200 & 200 \\
& Missing & 0 & 0 & 0 & 0 & 0 \\
\hline
\end{tabular}

\subsubsection{Gender}

Table 9 outlines the results obtained from demographic data on gender. 100 males and 100 females participated on the questionnaire as shown below.

Table 9. Gender Statistics

\begin{tabular}{clllll}
\hline & Frequency & Percent & Valid Percent & Cumulative Percent \\
\hline Valid & Male & 100 & 50.0 & 50.0 & 50.0 \\
& Female & 100 & 50.0 & 50.0 & 100.0 \\
& 200 & 100.0 & 100.0 & \\
\hline
\end{tabular}




\subsubsection{Age}

Table 10 outlines the results obtained from demographic data on Age. 64 responses from total responses were between 26 and 31 years which was the largest slice of the sample size. Then, 52 responses were between 32 and 36 years. In the third rank, the responses between 37 and 41 years were 36. 28 responses were more than 41 years. The lower slice of the sample size was 20 responses between 20 and 25 years.

Table 10. Age statistics

\begin{tabular}{llllll}
\hline & & Frequency & Percent & Valid Percent & Cumulative Percent \\
\hline Valid & $20-25$ & 20 & 10.0 & 10.0 & 10.0 \\
& $26-31$ & 64 & 32.0 & 32.0 & 42.0 \\
& $32-36$ & 52 & 26.0 & 26.0 & 68.0 \\
& $37-41$ & 36 & 18.0 & 18.0 & 86.0 \\
& More than 41 & 28 & 14.0 & 14.0 & 100.0 \\
& Total & 200 & 100.0 & 100.0 & \\
\hline
\end{tabular}

\subsubsection{Work Experiences}

Table 11 outlines the results obtained from demographic data on work experiences. The largest percent was $34 \%$ for responses that had work experiences among 11 and 20 years. The responses among 2 and 5 years work experiences and those among 6 and 10 years work experiences were so near. In addition, the lower percent was $12 \%$ for those had more than 21 years' work experiences.

Table 11. Work experiences statistics

\begin{tabular}{llllll}
\hline & & Frequency & Percent & Valid Percent & Cumulative Percent \\
\hline Valid & $2-5$ years & 56 & 28.0 & 28.0 & 28.0 \\
& $6-10$ years & 52 & 26.0 & 26.0 & 54.0 \\
& $11-20$ years & 68 & 34.0 & 34.0 & 88.0 \\
& More than 21 years & 24 & 12.0 & 12.0 & 100.0 \\
Total & 200 & 100.0 & 100.0 & \\
\hline
\end{tabular}

\subsubsection{Qualifications}

Table 12 outlines the results obtained from demographic data on qualifications. More than half of total responses have a Bachelor degree. 60 responses have a Master degree and 20 responses have a diploma degree. Only 4 responses have a high school which share with $\mathrm{PhD}$ responses on the lower rank in this statistics.

Table 12. Qualification Statistics

\begin{tabular}{lllll}
\hline & Frequency & Percent & Valid Percent & Cumulative Percent \\
\hline Highschool & 4 & 2.0 & 2.0 & 2.0 \\
Diploma & 20 & 10.0 & 10.0 & 12.0 \\
Bachelor & 112 & 56.0 & 56.0 & 68.0 \\
Master & 60 & 30.0 & 30.0 & 98.0 \\
PhD & 4 & 2.0 & 2.0 & 100.0 \\
Total & 200 & 100.0 & 100.0 & \\
\hline
\end{tabular}

\subsubsection{Job Position}

Table 13 outlines the results obtained from demographic data on job position. The largest slice of responses was employee by $46 \%$ of total responses. $24 \%$ of responses were head of department, and $22 \%$ of responses were supervisor. The lower slice of responses was director by $8 \%$ only. 
Table 13. Job Position Statistics

\begin{tabular}{lllcc}
\hline & Frequency & Percent & Valid Percent & Cumulative Percent \\
\hline Employee & 92 & 46.0 & 46.0 & 46.0 \\
Supervisor & 44 & 22.0 & 22.0 & 68.0 \\
Head of a Department & 48 & 24.0 & 24.0 & 92.0 \\
Director & 16 & 8.0 & 8.0 & 100.0 \\
Total & 200 & 100.0 & 100.0 & \\
\hline
\end{tabular}

\subsubsection{Data analysis of Participate Opinions}

The Second part of questionnaire is Participate Opinions which showed the personal thinking of the influence of ISO 9000 on employee performance and overall productivity. Moreover, it showed the main reason for adopting ISO 9000 standards. By using SPSS, the researcher analyzed the data to present the findings of respondents' answers.

a) The relationship between ISO 9000 and employee performance.

To know the opinions of participates on the relationship between ISO 9000 and employee performance; the following question could be raised:

-Do you think that using quality management system ISO 9000 can improve the employee performance?

The results of that question were shown in the Table 14.

Table 14. The relationship between ISO 9000 and employee performance

\begin{tabular}{lllll}
\hline & Frequency & Percent & Valid Percent & Cumulative Percent \\
\hline Yes & 176 & 88.0 & 88.0 & 88.0 \\
No & 24 & 12.0 & 12.0 & 100.0 \\
Total & 200 & 100.0 & 100.0 & \\
\hline
\end{tabular}

176 respondents believe that there is positive impact of implementing ISO 9000 on employee performance. On the other hand, only 24 from 200 respondents which are $12 \%$ of total sample think that no influence of ISO 9000 on employee performance.

b) The relationship between ISO 9000 and the organization productivity.

To know the opinions of participates on the relationship between ISO 9000 and organization productivity; the following question could be raised:

- Does the organization improve the overall productivity of their employees if it applied ISO $9000 ?$

The results of that question were shown in the Table 15.

Table 15 . The relationship between ISO 9000 and organization productivity

\begin{tabular}{lllll}
\hline & Frequency & Percent & Valid Percent & Cumulative Percent \\
\hline Yes & 168 & 84.0 & 84.0 & 84.0 \\
No & 32 & 16.0 & 16.0 & 100.0 \\
Total & 200 & 100.0 & 100.0 & \\
\hline
\end{tabular}

168 respondents believe that there is positive influence of implementing ISO 9000 on organization productivity. On the other hand, only 32 from 200 respondents which are 16\% of total sample think that no influence of ISO 9000 on organization productivity.

c) The main reason for adopting the ISO 9000 standards.

To know the opinions of participates on the main cause for adopting ISO 9000 standards; the following question could be raised:

- What was the main reason for adopting the ISO 9000 standards? 
The results of that question were shown in the Table 16.

Table 16. The main reason for adopting the ISO 9000 standards

\begin{tabular}{llccl}
\hline & Frequency & Percent & Valid Percent & Cumulative Percent \\
\hline Valid to gain advantages & 40 & 20.0 & 20.0 & 20.0 \\
Best Practice & 76 & 38.0 & 38.0 & 58.0 \\
Legal\&Regulatory compliance & 76 & 38.0 & 38.0 & 96.0 \\
Other & 8 & 4.0 & 4.0 & 100.0 \\
Total & 200 & 100.0 & 100.0 & \\
\hline
\end{tabular}

76 participates believe that the main reason for adopting ISO 9000 standards is to raise the operation level to best practice, while 76 participates believe that the main reason is to ensure legal and regulatory compliance. Moreover, 40 respondents think that the main reason is to gain advantages. In addition, only 8 out of 200 respondents believe that there are other different reasons.

\section{Correlation Analysis}

The strength and direction of the association between variables will appear when using correlation analysis. It determines how these variables are related to each others. The Pearson correlation will indicate how far all these data point are away from the line of the best fit.

Table 17. Correlation between each independent variable with organizational performance

\begin{tabular}{|c|c|c|}
\hline & & OP \\
\hline \multirow{2}{*}{$\mathrm{CF}$} & Pearson Correlation & $.832^{(* *)}$ \\
\hline & Sig.(2-tailed) & .000 \\
\hline \multirow{2}{*}{ LE } & Pearson Correlation & $.784^{(* *)}$ \\
\hline & Sig.(2-tailed) & .000 \\
\hline \multirow{2}{*}{ IP } & Pearson Correlation & $.715^{(* *)}$ \\
\hline & Sig.(2-tailed) & .000 \\
\hline \multirow{2}{*}{ CI } & Pearson Correlation & $.856^{(* *)}$ \\
\hline & Sig.(2-tailed) & .000 \\
\hline
\end{tabular}

** Correlation is significant at the 0.01 level (2-tailed).

As shown in Table 17, the result of Pearson Correlation between Customer focus (CF) and Organization Performance (OP) shows a positive and significant correlation $(r=0.832, \mathrm{p}$-value $<0.01)$. This means that the organization performance would be positively improved when the customer focus principle is employed. The result of Pearson Correlation between Leadership (LE) and Organization Performance (OP) shows a positive and significant correlation $(\mathrm{r}=0.784, \mathrm{p}$-value $<0.01)$. This means that the organization performance will be better improved when the Leadership principle is applied. The result on Pearson Correlation between Involvement of people (IP) and Organization Performance (OP) shows a significant positive correlation $(r=0.715$, $p$-value $<$ 0.01). This means that the organization performance will be better improved if the involvement of people principle is applied. Finally, the result of Pearson Correlation between Continual Improvement (CI) and Organization Performance (OP) shows a positive and significant correlation $(r=0.856, p$-value $<0.01)$. This means that the organization performance will be better improved when the Continual Improvement principle is applied.

\section{Regression Analysis}

This part provides the questionnaire results. The researcher will present results of the Regression Analysis.

\subsection{Ordinary Least Squares Analysis}

The regression analysis used to test the impact of each independents variable on the dependent variable.

Table 18 summarized the results of the Ordinary Least Squares (OLS) analysis. 
Table 18. Ordinary Least Squares (OLS) Analysis

\begin{tabular}{rrlllll}
\hline \multirow{3}{*}{ Model 1} & $R$ & $R$ square & F-Sig. & $B$ & $t$-Sig. \\
& Model 1 & $.880(\mathrm{a})$ & .774 & $.000(\mathrm{a})$ & & .109 \\
& (Constant) & & & .245 & .000 \\
& CF Mean & & & .314 & .103 \\
& LE & Mean & & & .131 & .450 \\
& IP & Mean & & & -.054 & .000 \\
\hline
\end{tabular}

a. Predictors: (Constant), CI_Mean, IP_Mean, LE_Mean, CF_Mean.

b. Dependent Variable: OP_Mean.

Table 18 indicates that the Regression analysis outputs presents the considerable model which estimated by F-Sig. $=0.000<0.01$ and the powerful correlation through the independent and dependent variables which estimated by $\mathrm{R}=0.880$. The coefficient of determination $R$ square is 0.774 showing that $77.4 \%$ of the difference in dependent variable (organization performance) was clarified by the independent variables. This means the difference between $(100 \%-77.4 \%)$ which is $22.6 \%$ will not involve in the model.

Moreover, Table 18 shows that there is evidence that both Customer Focus and Continual Improvement have effect on Organization Performance at $\alpha=0.01(t-S i g .=0.000<0.01)$. However, there isn't enough evidence that Leadership and Involvement of people have not any effect on organization Performance ( $t$-Sig. are equal to 0.103 and 0.450 which are greater than 0.01 ). The findings of regression indicated that organization performance is more explained by the variables Customer Focus and Continual Improvement than Leadership and Involvement of people. The effect of the four variables influence on organization performance was measured by linear regression test through this equation:

$$
\begin{gathered}
\text { Organization performance }=\beta 1 \text { Customer Focus }+\beta 2 \text { Leadership }+\beta 3 \text { Involvement of people }+\beta 4 \text { Continual } \\
\text { Improvement }+\varepsilon
\end{gathered}
$$

Linear regression is applied to put the dependent variable value based on its linear link to one predictor or more. As shown in Table 33, the four variables influence the organization performance is equal to:

$$
\begin{array}{r}
\text { Organization Performance }=0.314 \text { Customer Focus }+0.131 \text { Leadership }-0.054 \text { Involvement of people }+ \\
\text { 0.581Continual Improvement }+0.245
\end{array}
$$

The findings indicated the diversity influence on the organization performance was explained by the four variables.

\section{Results}

As a result, the research presented the descriptive statistics that reflected the frequencies of each item in demographic information (gender, age, work experiences, qualifications, and job position). Also, the data analysis of participates opinions showed the results of three questions in the second part of questionnaire. Then, the research used the correlation analysis to measure the force and direction of the association among variables, and to determine how these variables are closely together. Finally, to check the range of independent variables effect on the dependent variable, the researcher applied the regression test.

About the descriptive statistics, the researcher found that slice of participants, which answered the questionnaire, had variety of different ages, work experience, qualifications, and job positions, divided to 100 male and 100 female, and that means diversity of responses and perspectives to questions from the questionnaire, which was-in total- suitable for measurement and search environment. With all of these differences, $88 \%$ of the respondents confirm that ISO 9000 can improve the employee performance and $84 \%$ of the respondents believe that ISO 9000 can improve the productivity of the employees, which the results reflected positive perceptive to implementing ISO 9000 . Also, $38 \%$ of the respondents think that the major reason for applying ISO 9000 is to get best practice, which another $38 \%$ of the respondents think that it is to ensure legal and regulatory compliance.

Then, the research presented correlation analysis which reflected positive relationship between the four ISO 9000 principles and organization performance, which equals $0.832,0.784,0.715$ and 0.856 , and all of Sig scores were less than 0.01 . 
Finally, the results of regression analysis showed a strong influence of customer focus and continual improvement on organization performance which the p-value appeared below than 0.01 and it was more than 0.01 for leadership and involvement of people that lead to decide that there is no directly effect on the performance.

\section{Discussion}

Based on the results shown on our quantitative data analysis, Table 19 summarizes explicit strategies that were anticipated for improving and promoting a paradigm alteration in Bahrain's Council of Representatives performance.

Table 19. Explicit strategy for the council of representatives development in Bahrain

\begin{tabular}{ll}
\hline Explicit Strategy & Short Explanation \\
\hline Customer Focus & $\begin{array}{l}\text { ISO } 9000 \text { obligated the top management as a responsibility to guarantee that customer needs } \\
\text { are specified and met for them to achieve the customer gratification goal. In case of Council of } \\
\text { Representatives, the staff work on the preparation of the ISO } 9000 \text { requirements found in the } \\
\text { pilot phase of the application of the standards high rate of customer satisfaction for internal } \\
\text { services in the Council. The researcher found that a customer focus had directly effect on the } \\
\text { performance and overall satisfaction. } \\
\text { Leadership has no effect on organization performance. This is because there is lack of lead and } \\
\text { support from top management, lack of involving with employees to achieve the goals, less } \\
\text { maintaining internal environment, so the leadership role of top management disappears. These } \\
\text { are the reasons of disbelief of the leadership influence on performance. } \\
\text { Involvement of people has no effect on organization performance. This is because due to } \\
\text { misunderstanding of the importance for involving people and their abilities at all levels, and } \\
\text { the benefits that would come afterwards. Also, lack of motivated people, and sometimes the } \\
\text { monopoly in issuing decisions without the involvement of staff affected on the respondents' } \\
\text { perception. } \\
\text { Continual improvement has effect on organization performance. This is because staff, who are } \\
\text { working on the preparation of ISO 9000 requirements, find in the pilot phase of application of } \\
\text { the standards high rate of continual improvement for workflows, procedures, and delivering } \\
\text { services in the council, so the researcher found that a continual improvement had directly } \\
\text { effect on the performance. }\end{array}$ \\
\hline Continual Improvement
\end{tabular}

\subsection{Managerial Implications for Place Development}

Based on the study, the findings carry a managerial message. The researcher can conclude that for those who are interested in applying ISO 9000 standards in the organizations should focus on ensuring that all employees should understand the purpose of applying it as a tool to improve their products and services, along with satisfying the customer's need. Hence, the quality will be stably improved. In this case study, the researcher find a resistance of change and lack of understanding on the main idea of ISO 9000 because of weak delivering or misconception like some of employees' refusal of implementing ISO 9000 who have thought that restrictions are not guidance. Also, Council of Representatives should train its staff to fill in the ISO 9000 documents that are required from them, record the services on the log, and train some employees to audit all data recorded in the report of log as an internal auditors to get ready for external auditors.

In addition, Council of Representatives should emphasis its efforts on completely realizing the goals of implementing the standards during continuously improving operations, the environment, highly emphasis on satisfying customers, increasing the prevention, reducing the disclosure of non-conformities, and growing up the effectiveness of ISO 9000.

\subsection{Conclusion}

The main target of study was to identify the influence of ISO 9000 on the organization's performance by measuring the impact of four main principles which were customer focus, leadership, involvement of people, and continual improvement. The aim was to highlight the significance of implementing ISO 9000 standards which provided benefits and features for any certified organization. Also, to motivate the non-certified organizations apply the ISO 9000 standards, which would lead these organizations to compete with other organizations in 
improving the level of practices and ensure legal and regulatory compliance. This study evaluated the effect of implementing ISO 9000 on the performance of Council of Representatives in Kingdom of Bahrain. The researcher accepted the hypotheses of Customer Focus and Continual Improvement which had positive effect on Organization's Performance, and rejected the hypotheses of Leadership and Involvement of people as they had no effect on the performance. The researcher referred this rejection of the two hypotheses to the resistance of change and lack of understanding on the main idea of ISO 9000 due to weak delivering or misconception. The Council of Representatives could solve these problems by deliver the right conception of ISO 9000 to all staff and support it from top management to understand the purpose of applying it. The Council of Representatives should focus on obtaining the goals of ISO 9000 standards, during constantly developing operations, satisfying customers, and increasing the prevention and decreasing the exposure of non-conformities, to increase the level of operationally performance and overall productivity.

\subsection{Recommendation}

After reviewing and summarizing the results of the study, the author will provide some recommendations to help organizations before implementing ISO 9000 standards. First, when the organization decides to get ISO certification, it has to understand the information about ISO 9000 and its requirements, and determine its scope and permissible exclusions. Second, the organization should put an effective plan to achieve all stages within time to get the certification by taking into consideration the impact of its position before and after implementation. Third, the organization has to take into account the conformity of the workflows and procedures with all documents required to get ISO 9000 such as the policy, goals, manual, procedures, some documents and statements to guarantee the active planning, processes and monitor it, as well as the records required. Fourth, the organization has to appoint internal auditors to correct mistakes and errors, and prepare the internal audit program that shall be implemented periodically. Last but not least, the organization should identify areas for continual improvement rather than wait for problems and it shall put different treatment and preventive plans for the future. Based on the case study of this research, the top management shall take the role of leadership, and preserve an obligation and effective participation. In addition, the organization has to inform its employees about the decision of having ISO 9000 certification, and involve them from the beginning. Finally, the concerned part to apply the ISO 9000 requirements in the organization shall explain the ISO components, features, and returned benefits to all employees in order to avoid any problem such as the resistance toward changing or misunderstanding.

\section{Acknowledgments}

This paper significantly promoted from the perceptive feedback of lecturers, and administration staff at Ahlia University, notably, Qassim and Malak Jaffer. We also thank the participants at the Council of Representatives of Kingdom of Bahrain for their keen greeting of interest.

\section{References}

Alvesson, M., \& Kärreman, D. (2016). Intellectual Failure and Ideological Success Organization Studies: The Case of Transformational Leadership. Journal of Management Inquiry, 25, 139-152. https://doi.org/ $10.1177 / 1056492615589974$.

Black, K. (2012). Business Statistics for Contemporary Decision Making (7th ed.). USA: John Wiley \&Sons, Inc.

Cagnazzo, T., \& Fuiano. (2010). Benefits, barriers and pitfalls coming from the ISO 9000 implementation: the impact on business performances. Wseas Transactions on Business and Economics, 7(4).

EL Hajjar, S. (2016). A Pilot Study to Develop a Reliable Scale that Measures the Influence of Using Technology on Student's Performance in Learning Statistics. International Conference on Arts, Education and Social Science (ICAES) Barcelona, Spain. $\quad$ Retrieved from http://researchworld.org/Conference/2016/Spain/1/ICAES/

Houdek, P. (2016). What comes to a Manager's Mind: Theory of Local Thinking? Journal of Management Inquiry, 25, 359-366. https://doi.org/10.1177/1056492616640380

ISO. (2005). ISO 9000:2005 Quality management systems- Fundamentals and vocabulary (4th ed.).

ISO. (2008). ISO 9001:2008 Quality management systems - Requirements. ISO, Geneva, Switzerland.

ISO. (2009a). ISO 9004:2009 Managing for the sustained success of an organization -A quality management approach. ISO, Geneva, Switzerland.

ISO. (2009b). Selection and use of the ISO 9000 family of standards. Retrieved April 3, 2014. From 
http://www.iso.org/iso/iso_9000_selection_and_use-2009.pdf

ISO. (2011). ISO 19011:2011 Guidelines for auditing management systems. ISO, Geneva, Switzerland.

ISO. (2012). Quality management principles. Retrieved April 3, 2014 http://www.iso.org/iso/qmp_2012.pdf.

ISO. (2014). ISO9000-Quality management. Retrieved July $7, \quad 2014$ from http://www.iso.org/iso/home/standards/management-standards/iso_9000.htm

Lee, C., Lee, J., \& Lee, A. (2013). Statistics for business and financial economics. New York, NY: Springer.

Mangula, M., (2013). Tanzania. International Journal of Technology Enhancements and Emerging Engineering Research, 1 (1).

Ollila, A. (2012). Proposals for the implementation and improvement of ISO 9001. Global Journal of business research, 6(2). Aalto University, Finland.

Piskar, F. (2007). The Impact of the Quality Management System ISO 9000. Slovenia. Managing Global Transitions, 5(1), 45-61.

Schumacker, R. (2015). Learning statistics using R. London: Sage publications, Inc.

Zikmund, W. (2011). Business research methods. Mason, OH: Thomson/South-Western.

\section{Copyrights}

Copyright for this article is retained by the author(s), with first publication rights granted to the journal.

This is an open-access article distributed under the terms and conditions of the Creative Commons Attribution license (http://creativecommons.org/licenses/by/4.0/). 